\title{
MICOSES DO SISTEMA NERVOSO CENTRAL
}

\author{
DADOS ANATOMOPATOLOGICOS DA CRIPTOCOCOSE E \\ ASPERGILOSE CEREBRAIS
}

\begin{abstract}
ARISTIDES CHETO DE QUEIROZ*
ANA MARIA BLANCO MARTINEZ**
\end{abstract}

Torna-se cada vez mais frequente a ocurrência de infeç̧ões micóticas oportunistas em material de autópsia, provavelmente em consequência do uso mais amplo de drogas determinantes de baixa da resistência orgânica, como é o caso dos imunossupressores e citostáticos em pacientes já debilitados por doenças crônicas e caquetizantes 13,14,18. O SNC é local que com frequência mostra-se envolvido nas infecções micóticas profundas e oportunistas 7,9-12,15-18. A maioria dos trabalhos, principalmente aqueles da literatura nacional divulgam estes conhecimentos mediante estudos de casos isolados 4,6,8-12,16,17, apresentando aspectos clínicos das micoses ou discutindo a identificação laboratorial dos fungos e só mais raramente mostram aspectos anatomopatológicos destas afecções $2,10,12,17$. Isto torna difícil a avaliação da frequência com que este envolvimento aparece e, mais ainda, dificulta o conhecimento das variações morfológicas das reações tissulares produzidas pelos fungos ao nivel do tecido nervoso, contribuindo para fortalecer o conceito de que a caracterização morfológica dos fungos só pode ser feita exclusivamente mediante cultura, embora alguns trabalhos já chamem atenção para a importância do histologista na caracterização morfológica destes parasitos ${ }^{3,13,18}$. Por isso mesmo torna-se cada vez mais importante a divulgação de conhecimentos mostrando a caracterização morfológica dos fungos nos tecidos e as alterações histopatológicas por eles determinadas.

Este trabalho tem por finalidade apresentar o estudo anatomopatológico do envolvimento do sistema nervoso central nas micoses profundas observados em material de autópsia contribuindo para mostrar a sua frequência e as variações da resposta tissular que podem aparecer.

\section{MATERIAL E METODOS}

Foram selecionados para o estudo 64 casos de micoses profundas e oportunistas registrados durante o periodo de 1949 a 1976, quando foram realizałas 3.966 autópsias.

Trabalho realizado no Serviço de Anatomia Patológica do Hospital Prof. Edgard Santos, Salvador-BA: "Professor Assistente do Departamento de Anatomia Patologica e Medicina Legal da Universidade Federal da Bahia, bolsista do Conselho Nacional de Desenvolvimento Científico e Tecnológico $\left(\mathrm{CNP}_{\mathrm{q}}\right)$; **Estagiária do Serviço de Anatomia Patológica do Hospital Prof. Edgard Santos, bolsista do $\operatorname{CNP}_{q}$. 
Dos 64 casos apenas 42 preencheram os critérios para o estudo, isto é possuiam dados clínico-patológicos suficientes, bem como laminas e blocos disponíveis para a revisão histopatológica. Os prontuários clínicos foram revistos para obtenção de dados clínicolaboratoriais e os protocolos de autópsias também revistos para obtenção de dados macroscópicos gerais e, em particular, do encéfalo. Todos os casos haviam sido submetidos a autópsias completas com estudo sistemático macro e microscópico de todos os órgãos. As lâminas dos casos selecionados foram reestudadas com coloração pela hematoxilina e eosina, P.A.S. e Grocott, para melhor caracterização morfológica do tipo do fungo. Novos cortes foram realizados quando necessário para melhor estudo de aspectos histopatológicos das lesñes e da identificação Lo fungo.

\section{RESULTADOS}

A tabela 1 mostra a distribuição dos 42 casos estudados de acorło com os tipos de micose, e sua relação com o envolvimento do SNC. Dos 5 tipos diferentes de micoses existentes neste material, apenas a criptococose e a aspergilose determinaram comprometimento do encéfalo.

\begin{tabular}{lcc}
\hline Tipo da micose & $\begin{array}{c}\text { Ne de casss } \\
\text { estudados }\end{array}$ & $\begin{array}{c}\text { No casos com } \\
\text { cnvolvimento do SNC }\end{array}$ \\
\hline \hline Candidiase & 24 & 0 \\
Criptococose & 9 & 8 \\
Aspergilose & 5 & 2 \\
Histoplasmose & 2 & 0 \\
Blastomicose & 1 & 0 \\
Candidiase associada & & 0 \\
a aspergilose & 1 & 0 \\
\hline
\end{tabular}

Tabcla 1 - Envolvimcnto do SNC nos 42 casos estudados de micose profundas $e$ oportunistas

$\mathrm{Na}$ tabela 2 estão expressos os principais dados clínico-patológicos dos casos de criptococose, mostrando que o envolvimento do SNC apareceu em 8 dos 9 casos existentes. Po Le-se observar que em 4 deles a criptococose do encéfalo representou a doença básica principal. Os demais casos foram observados em pacientes com doenças básicas pré-existentes e correspondem aos casos sem manifestações neurológicas. Do ponto de vista anatomopatológico, 6 casos apresentaram envolvimento predominante de leptomeninges com pequeno comprometimento do tecido nervoso. Nestes casos os encéfalos se apresentaram com espessamento leitoso e irregular de meninges de intensidade variável, com alargamento do espaço subaracnoideano, particularmente da parte profunda dos sulcos cerebrais onde se coletava material viscoso. $O$ envolvimento do tecido nervoso foi observado de maneira pouco proeminente e sob a forma de múltiplas pequenas vesiculas no cortex cerebral (Fig. 1). O aspecto histológico nestes 6 casos era característico de meningite crônica com presença de grande quantidade de parasitos alargando o espaço subaracnoideano. A reação inflamatória apresentou variação de intensidade sendo discreta em alguns casos e intensa em outros e representada pela presença de linfócitos, plasmócitos e histiócitos (Fig. 2). Frequente foi o achajo de células gigantes em 5 destes casos e sempre apresentando parasitos no citoplasma. Em um destes casos o comprometimento do tecido nervoso estava representado por formação granulomatosa com necrose central e com células gigantes na periferia além da reação inflamatória crônica inespecifica. 


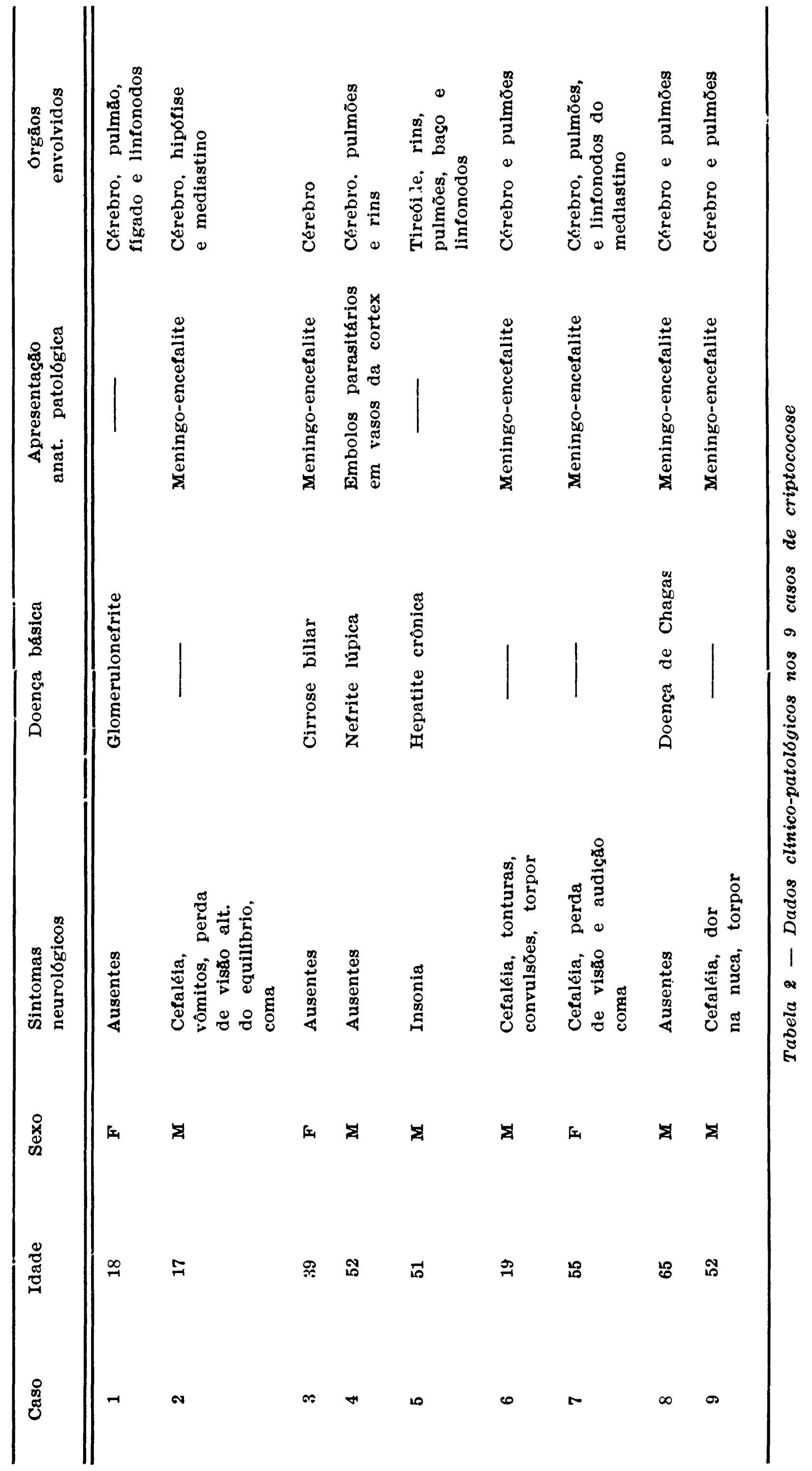




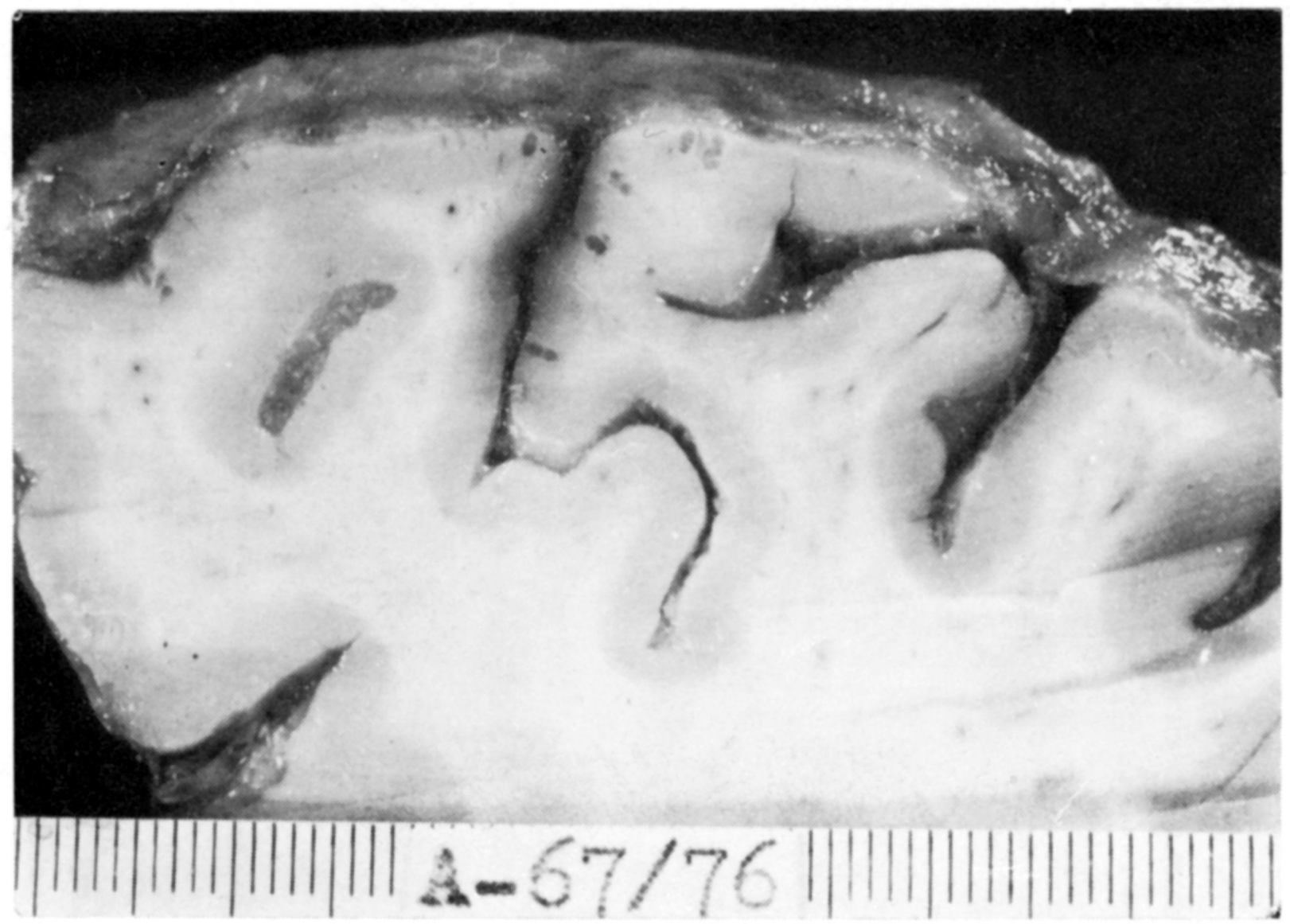

Erig. 1 -- 8uperficie de corte do cérebro em caso de criptococose, mostrando espessamento de meninges, alargamento dos sulcos e envolvimento focal da cortex $80 b$ a forma de pequenas vesiculas.

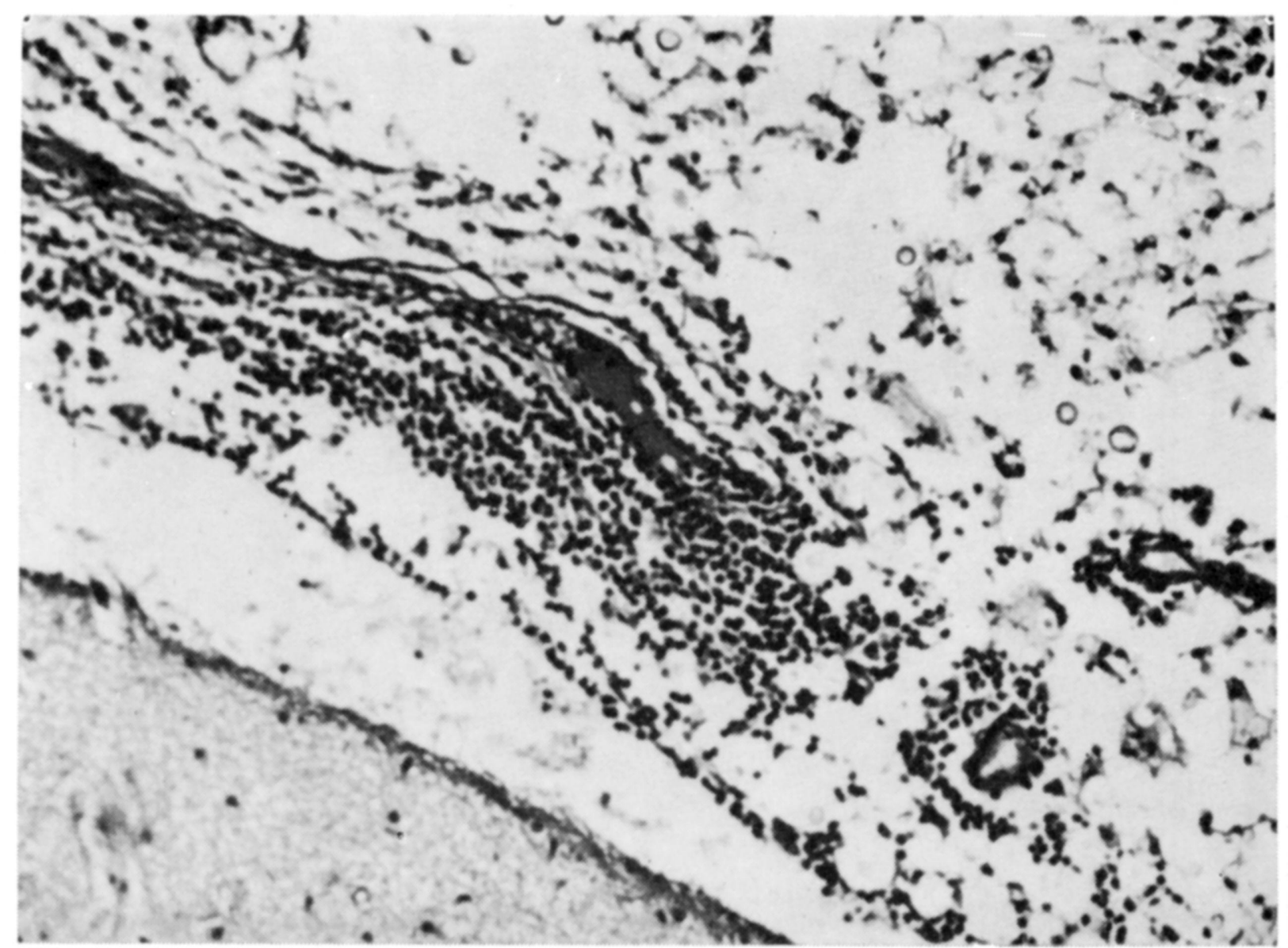

F'ig. - $A$ seçăo mostra, no espaco subaracnoideano, grande número de criptococos ao lado de adensamento focal de células linfocitarias (HE $x$ 200). 
Os plexos coróides dos ventrículos laterais foram estudados em 3 casos e apresentaram envolvimento em 2, com lesão granulomatosa onde os parasitos foram encontrados inclusive no interior do citoplasma de cŕlulas grigantes.

Os outros dois casos tiveram apresentação anatomopatológica diferente destes acima apresentalos. Num deles (caso 1), os parasitos foram encontrados de maneira bem escassa na meninge sem qualquer reação celular inflamatória. No outro (caso 4). os parasitos foram encontrados isolados ou em pequenos grupos no interior de capilares da cortex cerebral, sem mostrar também qualquer reaçăo tissular ou inflamatória (Fig. 3).

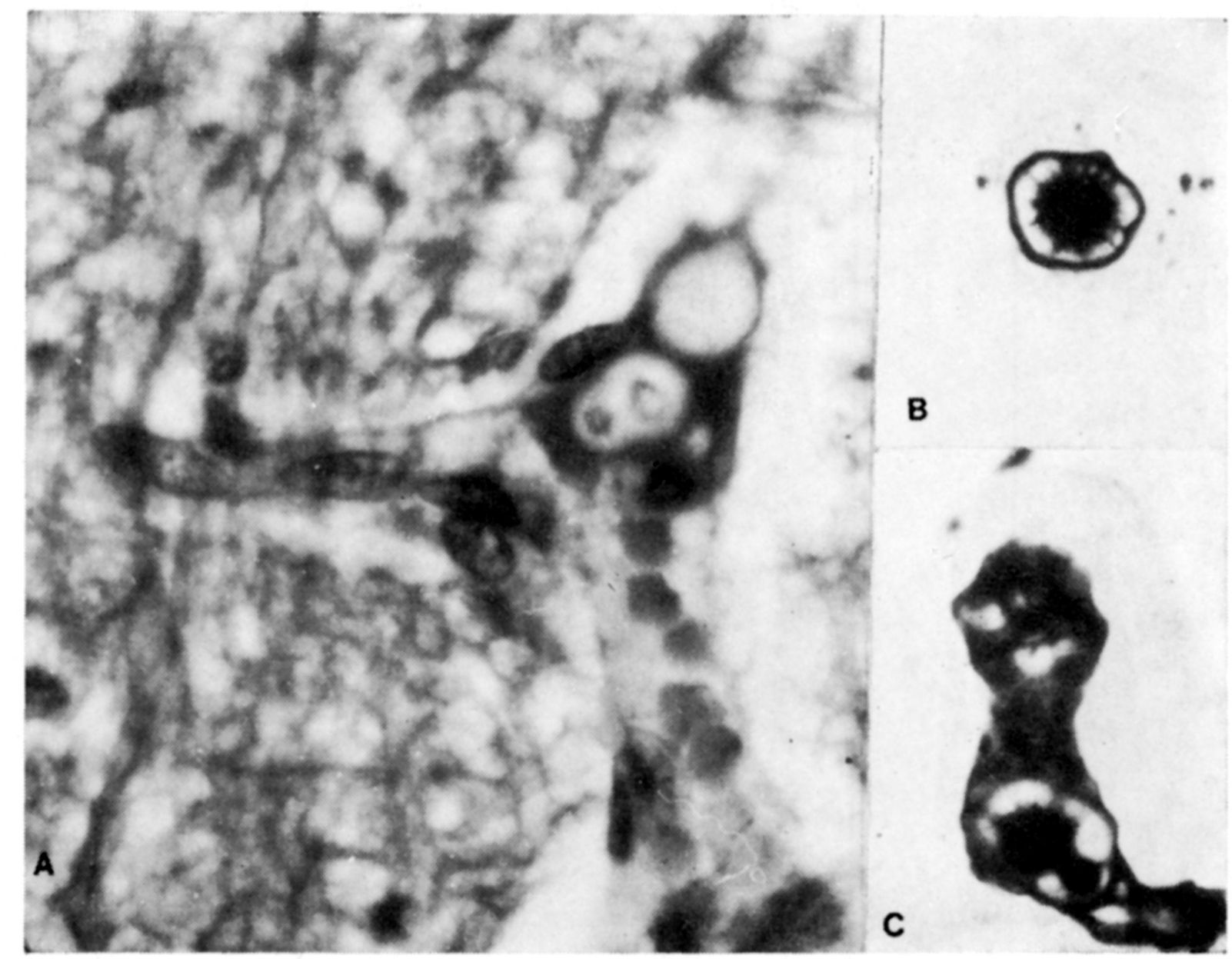

Fig. :3-Presenca de criptococos no interior de capilares do tecido nervoso cerebral [HE (A) e Grocott (B e C) $x \quad 400]$.

A tabela 3 apresenta os principais dados clinicopatológicos dos 5 casos de aspergilose, mostrando o comprometimento do SNC em 2 deles. A apresentação anatomopatológica destes casos se fez sob a forma de meningoencefalite e cle encefalite necrotizante extensa. No caso 1 o envolvimento foi exclusivo do cérebro. Na meninge observou-se extensa reação inflamatória com grande comprometimento vascular por trombose oclusiva, identificando-se al grande número de hifas. Estas eram grossas, septadas e com dicotomização em ângulo agudo e comprometiam paredes e luzes vasculares. No tecido nervoso a lesão mostrou aspecto necrotizante e hemorrágico com grande quantidade de fungos, mas com pouca reação inflamátória, sendo proeminente o comprometimento vascular pelas hifas que atravessavam a parede, atingindo a luz (Fig. 4). No caso 5, a disseminação era sistêmica apresentando extenso comprometimento cerebral além do envolvimento de rins, pulmões e coração. Neste caso não houve comprometimento meníngeo estanđo a lesão representada por extensas áreas necrotizantes envolvendo a substância branca do hemisfério cerebral esquerdo, onde o tecido nervoso se mostrava bastante friável (Fig. 5). O exame histológico mostrou extensos focos de 
334 ARQ. NEURO-PSIQUIAT. (SAO PAULO) VOL. 35, No 4, DEZEMBRO, 1977

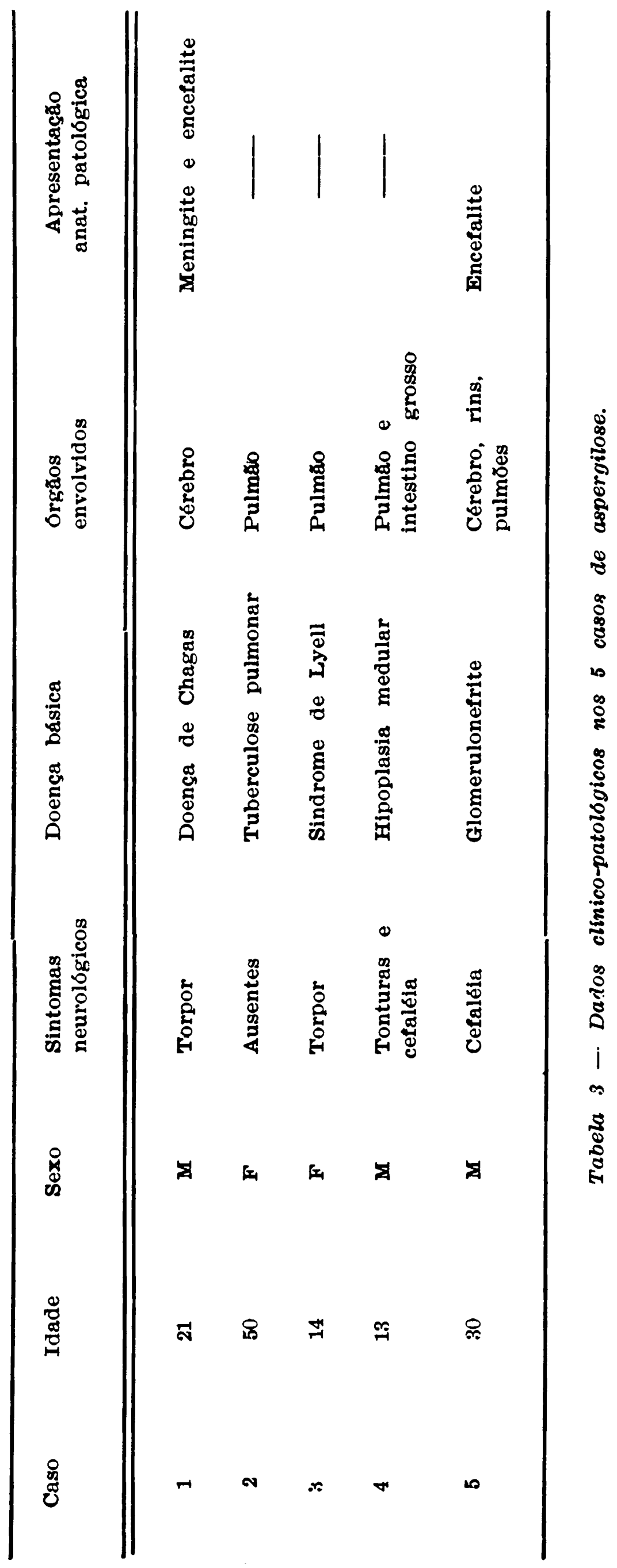




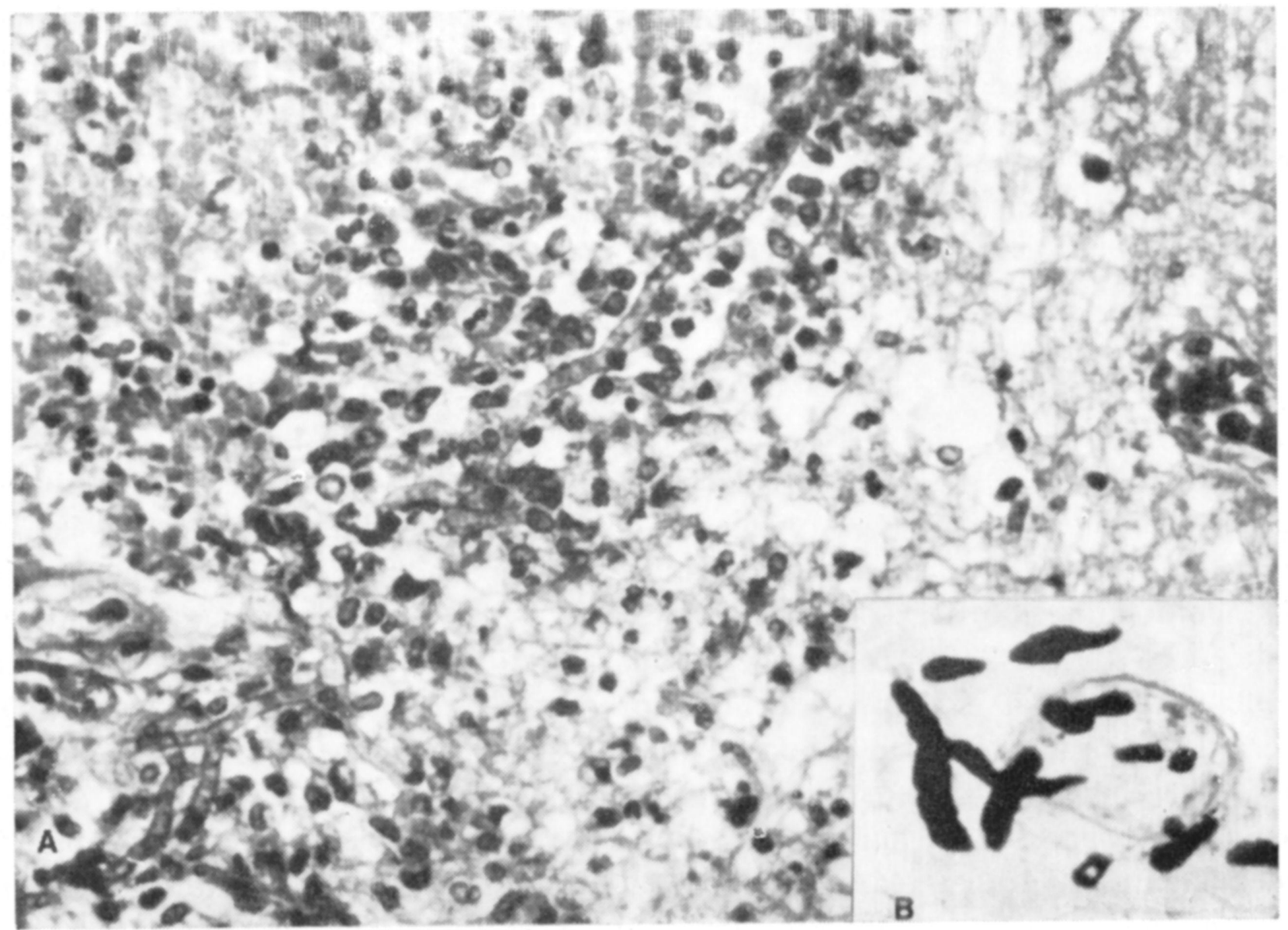

Fig. 4 - Lesån necrotizante do tecido nervoso em caso de aspergilose. Observar as hifas largas, septadas $e$ dicotomizadas em angulo agudo (A), com invasão de paredes vasculares (B) [HE e Grocott $x_{400] \text {. }}$

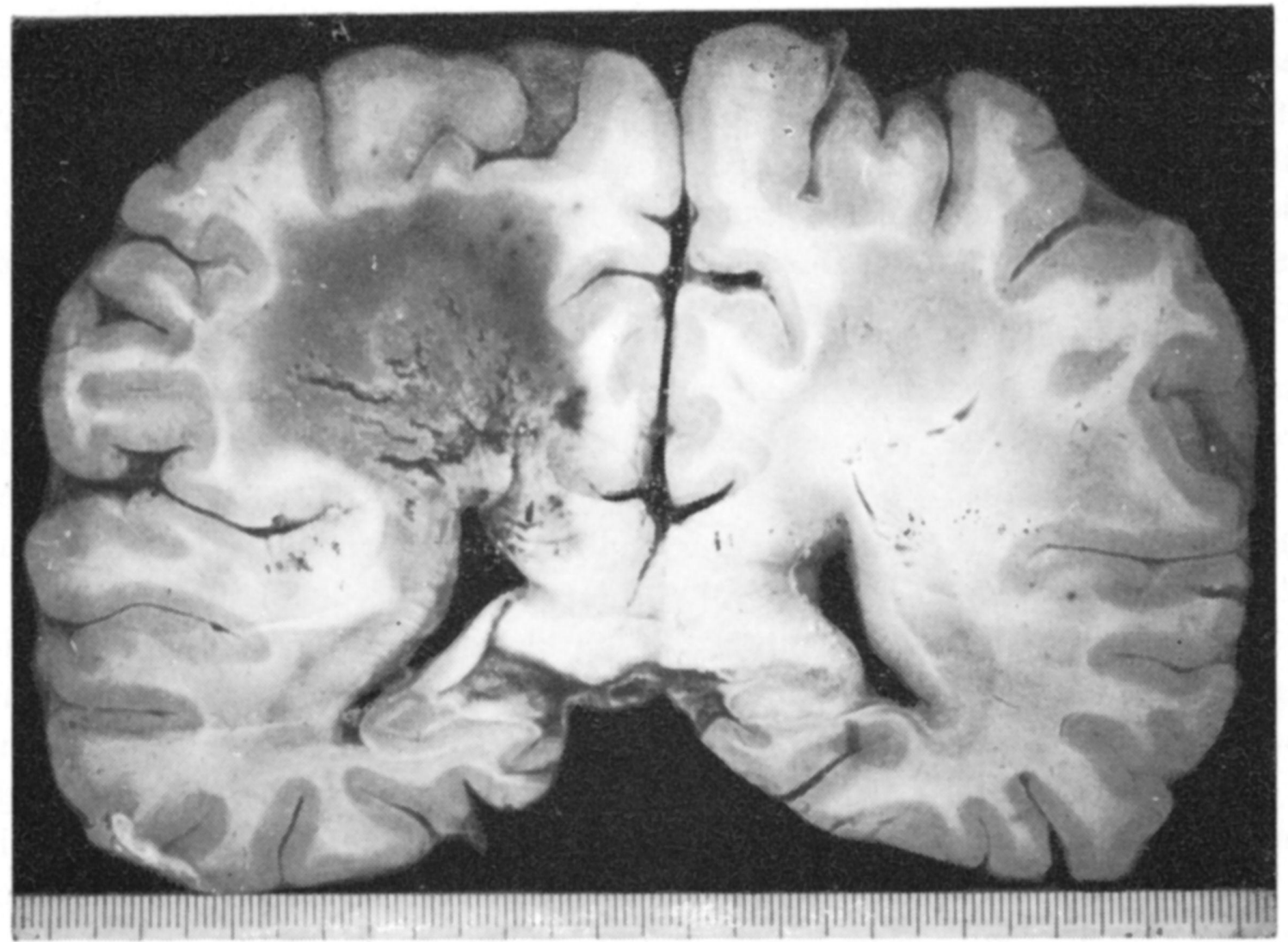

Fig. 5 - Secç̃o do cérebro em caso de aspergilose disseminada: observar a extensa lesão necrotizante envolvendo a substancia branca do hemisfério esquerdo. 
necrose recente com vasos congestos e por vezes ocluidos por trombos, com moderada reação inflamatória estando presentes polimorfonucleares, linfócitos e, mais raramente, plasmócitos. Foi grande o número de hifas identificadas nas áreas necróticas, as quais se apresentavam comprometendo paredes e luzes vasculares. Na grande maioria as hifas eram largas, septadas e com a ramificação em ângulo agudo.

Dos casos de candidiase, apenas dois se apresentaram com quadro de disseminação sistêmica da micose. Mesmo nestes casos não houve comprometimento do sistema nervoso.

\section{COMENTARIOS}

A análise do nosso material mostrou que, contrário ao que está referido em alguns trabalhos 11,12,13, o envolvimento do SNC na candidiase é raro, pois nem mesmo nos casos com grande disseminação sistêmica da micose, houve comprometimento do tecido nervoso. Em relação à aspergilose observou-se o envolvimento do SNC em 2 dos 5 casos estudados, sendo que num deles o comprometimento cerebral foi exclusivo, sem comprometimento de outro qualquer órgão. A criptococose mostrou ser o tipo de micose mais frequente no comprometimento do SNC, sendo que 8 casos mostraram este tipo de envolvimento: em 4 a lesão do sistema nervoso se apresentou como doença primária sem outra condição pré-existente. A faixa etária entre 17 e 65 anos e a maior predominância no sexo masculino estão de acordo com o que está registrado na literatura ${ }^{5,7}$. O uso de drogas capazes de baixar a resistência orgânica, que tem sido implicada como determinante de susceptibilidade à infecção criptocócica, não foi observado no nosso material o que não impede de se admitir tal fato.

Excepto por algumas diferenças, os achados anatomopatológicos destes casos são superponíveis aos descritos anteriormente ${ }^{\tilde{s}, 6,7}$. Um dos aspectos mais interessantes deste material foi a existência em um caso, de grande embolização de parasitos na cortex cerebral (Fig. 3), o que mostra a importância da via hematogênica para a disseminação a partir de lesões em outros órgãos. Neste caso, a presença de lesões também nos rins, sugere que a disseminação sistêmica se fez por via hematogênica a partir das lesões pulmonares, existentes.

As alterações morfológicas tissulares nas micoses do SNC são muito variáveis, indo desde as reações mais intensas, com grande destruição tissular até a completa ausência de reação ${ }^{13}$. A inexistência de reação tissular é referida nas infecções por criptococos, particularmente no sistema nervoso, sendo os distúrbios clinicopatológicos decorrentes da proliferação local do parasito. Dois de nossos casos ilustram esta situação, um deles com parasitos na meninge e o outro com parasitos embolizando em vasos da cortex cerebral na ausência de qualquer reação tissular inflamatória. Outras vezes a reação inflamatória nesta micose é discreta e, quando aparece, se faz nos casos em que a doença teve curso mais prolongado ${ }^{*}$. No nosso material a reação inflamatória foi vista em 6 casos com intensidade variável, inclusive com aparecimento de células gigantes formando por vezes verdadeiros granulomas, não havendo qualquer relação com o tempo de doença. Outro aspecto interessante neste estudo de criptacocose foi o envolvimento dos plexos coróides visto em 2 dos casos, lesão 
que não está referida na literatura talvez pela falta de estudo sistemático desta estrutura.

O sistema nervoso representa local que com frequência è envolvido nas infecções por aspergilus 16,18, como parte de disseminação sistêmica da micose. Caracteristicamente, determinam o aparecimento de lesões agudas necrotizantes e graves pela tendência particular destes fungos de invadir paredes vasculares e determinar fenômenos trombóticos ${ }^{13,18}$. No nosso material, os achados são superponíveis aos existentes na literatura, o que comprova a predileção destes fungos pelo envolvimento de paredes vasculares.

Em resumo, este estudo mostra: 1) a baixa frequência de micoses profundas envolvendo o SNC a que ocorreu na proporção aproximada de 1/400 autópsias; 2) que a criptococose representa o tipo mais frequente de micose do SNC ocorrendo mesmo como doença básica primária, sendo seguida pela aspergilose; 3) a possibilidade de caracterização morfológica de fungos nos tecidos, chamando atenção para o papel do histologista em diagnosticar micoses no material de autópsia, particularmente em casos onde os fungos representam achado incidental, no estudo de rotina.

\section{RESUMO}

O trabalho mostra o envolvimento do SNC em 42 casos de micoses oportunistas em material de autópsia, sendo enfatizada a baixa frequência do comprometimento encefálico, o que apareceu na proporção aproximada de $1 / 400$ casos de autópsia. A criptococose apareceu como a micose mais frequente no envolvimento do SNC sendo encontrada em 8 dos 9 casos estudados, seguido pela aspergilose que comprometeu o encéfalo em 2 dos 5 casos estudados. Apesar do grande número de casos de candidiase examinados não hauve lesão encefálica por esta micose. $O$ estudo das alterações histológicas observadas nos casos de criptococos mostrou aspectos diferentes daqueles classicamente descritos nesta micose, com referência particular à existência de grande reação inflamatória com fợmação de células gigantes em grande número e, mais ainda, com referência ao envolvimento do plexo coróide observado em 2 casos. $O$ trabalho chama atenção para a possibilidade da caracterização morfológica dos fungos nos tecidos, mostrando a importncia do papel desempenhado pelo histopatologista no diagnóstico de micoses no material de autpsia, particularmente nos casos em que os fungos representam achado incidental no estudo de rotina.

\section{SUMMARY}

Mycosis of the central nervous system: clinicopathological data on cryptococcosis and aspergillosis of the brain

The pathological findings of the cerebral involvement in deep-seated fungal infections in routine autopsy is reported. In 42 cases of mycotic infections studied among 3.966 autopsies, there were 8 cases of cryptococosis and 2 of 
aspergillosis of the brain, showing a very low frequency of central nervous system involvement, occuring in a proportion of $1: 400$ autopsies. The histopathological findings of the brain in cases of cryptococosis showed the spectrum of inflamatory reactions already described, although most of the cases presented with mild to severe meningitis with large number of giant cells, and slight degree of involvement of the nervous tissue. The cases of aspergillosis showed a pattern of severe necrotizing meningo-encephalitis with large number of fungi. The paper points out the role of the histological examination in the identification of the fungi in tissues and their morphologic reactions.

\section{REFERENCIAS}

1. AlCANTARA, L. G. \& MONTEIRO, V. S. - Criptocococe pulmonar e nervosa: comentário em torno de dois casos. R. Fac. Mcd. Univ. Fed. Ceará: 105; 1969.

2. AMORIM, M. F. \& PASCUALUCCI, M. E. A. - Natureza das lesões do sistema nervoso central na torulose. Rev. Lat. Amer. Anat. Pat. 2:41, 1958.

3. BAKER, R. D. - Histoplasmosis in routine autopsies. Am. J. Clin. Path. 41:457, 1964.

4. BAKER, R. D. - Fungus infections of the central nervous System. In Minckler, J. editor - Pathology of Nervous System Vol. 3 pg si476. McGraw-Hill Book Co., New York, 1972.

5. BARANSKI, M. C.; SILVA, A. F.; SZPEITER N.; FERREIRA, J. A. \& SCHWEIDSON, J. - Criptococose do sistema nervoso central: apresentação de três casos. R. Soc. Bras. Med. Trop. 4 (supl.): 16, 1970.

6. DUARTE, E. - Criptococose generalizada: apresentaçăo de um caso de autópsia completa. Hospital (Rio de Janeiro) 43:345, 1953.

7. GIORGI, D. R.; REIS, J. B; BEI, A. \& REIS FILHO, J. B. - Criptococose do sistema nervoso central. Arq. Neuro_Psiquiat. (São Paulo) 32:77, 1974.

8. LACAZ, C. S.; BRITTO, T.; FARIA, J. L. \& LEFEVRE, A. B. - Micose do sistema nervoso central: registro de um caso associado a hidrocefalia. R. Inst. Med. Trop. (São Paulo) 12:161, 1970.

9. NIEMEXeR. P.; GONSAlves, G. J.; MADI, K.; DUARTE, F. \& PAOLA, D. Aspergiloma cerebral. Rev. Soc. Bras. Med. Trop. 7:1, 1973.

10. OLIVEIRA, H. A.; ALMEIDA, A. L. G.; LYRO, A. D. \& OliveirA, I. S. Blastomicose cerebral, forma tumoral. R. Med. H. S. E. (Rio de Janeiro) 23:247, 1971.

11. QUEIROZ, L. S.; NUCCI, A. \& FARIA, J. L. - Actinomicose cerebral. Arq. Neuro-Psiquiat. (Sð̊o Paulo) 33:336, 1975.

12. QUEIROZ, L. S.; NUCCI, A. \& FARIA, J. L. - Candidiase sistêmica com localizaçăo encefálica: estudo de 5 casos. Arq. Neuro-Psiquiat. (Sð̌o Paulo) 34:10, 1976.

13. SYMMERS, W. ST. C. - The tissue reactions in deep-seated fungal infections: the role of histological examination in mycologic diagnosis. Ann. Soc. Belge. Med. Trop. 44:869, 1964.

14. SOERENSEN, B.; CORReA, H. C. S. \& SALIBA, A. M. - Criptococose associada a moléstia de Hodgkin. Rev. Bras. Cirurg. 44:225, 1962. 
15. TOGNOLA, W.; LUCCA, F. \& MARLET, J. M. - Criptococose do sistema nervoso central: relato de dois casos. J. Bras. Med. 20:42, 1971.

16. WITTIG, E. O.; CAT, I. \& KASTING; G. - Meningoencefalite a aspergillus. Arq. Neuro-Pgiquiat. (Søo Paulo) 31:220, 1973.

17. WITTIG, E. O. - Meningoenccfalite a mucormicose. Arq. Neuro-Psiqutat. (Sฉ̆o Paulo) 31:15, 1973.

18. YOUNG, R. C.; BENNETT, J. E.; VOGEL, C. L.; CARBONE, P. P. \& DEVITA, V. T. - Aspergillosis: the spectrum of the disease in 98 patients. Medicine (Baltimore) 49:147, 1970.

Servico de Anatomia Patolboica - Hospital Prof. Bdgard Santos - $\$ 000$ Salvador BA - Brasil. 